\title{
Implante imediato com provisionalização e compensação tecidual em região estética - aspectos determinantes para o sucesso clínico: série de casos clínicos
}

Immediate implantation with provisionalization and tissue compensation in aesthetic region determining aspects for clinical success: clinical case series

Implantación inmediata con provisionalización y compensación de tejidos en región estética aspectos determinantes para el éxito clínico: serie de casos clínicos

Recebido: 18/12/2021 | Revisado: 26/12/2021 | Aceito: 02/01/2022 | Publicado: 03/01/2022

Cristine Haralambos Bassoukou ORCID: https://orcid.org/0000-0002-4583-336X Universidade Santo Amaro, Brasil Email: crisbassoukou@gmail.com

Graziele Parize

ORCID: https://orcid.org/000-0002-3463-7865

Universidade Santo Amaro, Brasil

Email: grazi.parize@hotmail.com

Daniella Pilon Muknicka

ORCID: https://orcid.org/000-0001-6791-7719

Universidade Santo Amaro, Brasil Email: muknicka@icloud.com

Heloisa Fonseca Marão

ORCID: https://orcid.org/000-0002-6128-8576

Universidade Santo Amaro, Brasil Email: hfmarao@prof.unisa.br

Debora Pallos

ORCID: https://orcid.org/000-0001-7426-1041

Universidade Santo Amaro, Brasil Email: dpallos@prof.unisa.br

Angelica Castro Pimentel

ORCID: https://orcid.org/000-0002-6317-6439

Universidade Santo Amaro, Brasil

Email: draangelicacp@uol.com.br

Wilson Roberto Sendyk

ORCID: https://orcid.org/000-0002-3742-1330

Universidade Santo Amaro, Brasil

Email: wilsen@terra.com.br

\begin{abstract}
Resumo
Introdução: Atualmente há uma crescente tendência para a instalação dos implantes imediatamente após a extração dentária, já que respeitando os princípios para a utilização de dita técnica, essa se mostra a reduzir o tempo de tratamento e diminuir a morbidade, uma vez que se elimina uma etapa cirúrgica. Objetivo: Relatar uma série de casos clínicos de instalação de implante imediato em região anterior maxilar, com provisionalização, enxerto ósseo com biomaterial, e compensação tecidual através de enxerto de tecido conjuntivo. Métodos: Após a instalação imediata dos implantes nos alvéolos frescos, realizou-se compensação tecidual através de enxerto ósseo e tecido conjuntivo. Coroas provisórias foram instaladas nos implantes devido ao excelente torque obtido na instalação deles. Após cinco meses, as próteses definitivas de cerâmica foram instaladas. Conclusão: Os implantes imediatos com provisionalização imediata apresentam resultados satisfatórios em região anterior com a utilização de biomaterial ósseo e enxerto de tecido conjuntivo.
\end{abstract}

Palavras-chave: Implante dentário; Estética dentária; Cerâmica.

\begin{abstract}
Introduction: Currently there is a growing trend for the installation of implants immediately after tooth extraction, since respecting the principles for the use of said technique, it has been shown to reduce treatment time and reduce morbidity, as it eliminates a surgical step. Objective: To report a series of clinical cases of immediate implant placement in the anterior maxillary region, with provisionalization, bone graft with biomaterial, and tissue compensation through connective tissue graft. Methods: After immediate installation of the implants in fresh alveoli, tissue compensation was performed using bone graft and connective tissue. Temporary crowns were installed on the implants due to the excellent
\end{abstract}


torque obtained in their installation. After five months, the permanent ceramic prostheses were installed. Conclusion: Immediate implants with immediate temporization present satisfactory results in the anterior region with the use of bone biomaterial and connective tissue graft.

Keywords: Dental implantation; Esthetics, dental; Ceramics.

\section{Resumen}

Introducción: Actualmente existe una tendencia creciente a la instalación de implantes inmediatamente después de la extracción del diente, ya que respetando los principios para el uso de dicha técnica, se ha demostrado que reduce el tiempo de tratamiento y reduce la morbilidad, ya que elimina un paso quirúrgico. Objetivo: Informar una serie de casos clínicos de colocación inmediata de implantes en región anterior maxilar, con provisionalización, injerto óseo con biomaterial y compensación tisular mediante injerto de tejido conectivo. Métodos: Después de la instalación inmediata de los implantes en alvéolos frescos, se realizó una compensación tisular mediante injerto óseo y tejido conectivo. Sobre los implantes se instalaron coronas provisionales debido al excelente torque obtenido en su instalación. Después de cinco meses, se instalaron las prótesis cerámicas permanentes. Conclusión: Los implantes inmediatos con temporización inmediata presentan resultados satisfactorios en la región anterior con el uso de biomaterial óseo e injerto de tejido conectivo.

Palabras clave: Implantación dental; Estética dental; Cerámica.

\section{Introdução}

A Odontologia vem avançado diariamente principalmente no âmbito tecnológico, com inúmeras novas soluções e técnicas para a resolução dos casos clínicos. A perda dental ainda ocorre por vários motivos, dentre eles a cárie, traumatismos, trincas, endodontias mal-sucedidas e problemas periodontais. A ausência de um elemento dental pode acarretar problemas nos tecidos moles e duros, principalmente nos três primeiros meses do processo de cicatrização. (Botilde, et al., 2020; Araújo et al., 2005).

Atualmente há uma tendência crescente para a inserção dos implantes imediatamente após a extração dental, pois respeitando-se os princípios para a utilização desta técnica, ela reduz o tempo de tratamento e diminui a morbidade uma vez que se elimina uma cirurgia (Bhoa 2008). Em muitos casos este procedimento pode ainda ser combinado com a provisionalização imediata. É provável que essa tendência por arrepiar os processos seja resultado da evolução de fatores sociais, pacientes cada vez mais exigentes e o desejo por resultados mais rápidos e imediatos.

O tempo para a instalação do implante e para a provisionalização tem influência direta nos tecidos periimplantares duros e macios, desafiando assim a estética e o resultado centrado no paciente. (Bonnet, et al., 2018; Nimwegen et al., 2018; Zuiderveld et al., 2020).

A inserção imediata do implante e a provisionalização em zonas estéticas é uma modalidade de tratamento bem documentada. O conceito é a preservação dos tecidos peri-implantares, especialmente o suporte da arquitetura gengival a fim de se manter um contorno natural e estético. Estudos revelaram que a inserção imediata do implante sem enxerto, culmina em uma reabsorção óssea horizontal pronunciada, e que alguns fatores podem interferir como o alinhamento dentro do alvéolo do implante (Noelken et al., 2017). A reabsorção horizontal ocorre principalmente na face vestibular, comprometendo assim a estética (Araujo et al., 2005). A fim de compensar esta remodelação óssea esperada, alguns autores propuseram o uso de enxertos de tecido conjuntivo em combinação com biomateriais (Botilde et al., 2020; Merheb et al., 2014). O uso de enxerto de tecido conjuntivo foi proposto em implante imediatos, a fim de estabilizar o nível gengival e compensar a perda de volume tecidual (Jiang et al., 2020).

Sendo assim, nos dias de hoje o enxerto de tecidos moles se tornou um tema de crescente interesse na Implantodontia. Os procedimentos cirúrgicos propostos visam o aumento do tecido queratinizado em volume, em locais de implantes dentários, para melhora da estética e da estabilidade biológica. (Giannobilde et al, 2018). A utilização dos enxertos de tecido conjuntivo em áreas de implantes imediatos foi proposta a fim de estabilizar o nível gengival e compensar a perda de volume de tecido (Jiang et al,2020). 
A perda do elemento dental acarreta uma redução da crista óssea alveolar independente da instalação imediata do implante. Enxertar a lacuna entre o implante e a parede óssea provou limitar a perda de volume da crista, o que pode beneficiar a estabilidade do nível gengival após a instalação do implante (Jiang et al, 2020; Nimwegen et al, 2018). A instalação imediata de implantes com simultânea regeneração óssea utilizando-se osso bovino desproteinizado mineral é um método previsível, além de favorecer resultados estéticos favoráveis. A utilização simultânea de enxerto de tecidos moles dos implantes imediatos pode reduzir o risco de deficiência na estética e recessão, favorecendo resultados satisfatórios. (Noelken et al, 2017).

O fenótipo gengival parece desempenhar um papel importante no colapso dos tecidos moles e no risco de recessão em torno de implantes imediatamente instalados. Os procedimentos cirúrgicos para aumentar o volume de tecido mole são recomendados na zona estética, principalmente para compensar esta perda de volume. O principal objetivo da terapia com implantes é obter saúde a longo prazo tanto nos tecidos moles quanto nos tecidos duros (Seyssens et al, 2021).

$\mathrm{O}$ presente estudo foi realizado para demonstrar a efetividade do implante imediato em área estética, com provisionalização e utilização de biomaterial associado à enxertia com tecido conjuntivo, como uma forma alternativa e eficaz de tratamento para dentes condenados em área estética, demonstrando resultados confiáveis e com ganhos significativos tanto na saúde do implante quando na saúde pepriimplantar da região.

\section{Metodologia}

\subsection{Relato de Caso 1}

Paciente do sexo masculino, 44 anos, compareceu ao atendimento queixando-se de mobilidade e fístula no elemento 21 (incisivo central superior esquerdo). O paciente não apresentava problemas sistêmicos. Ao exame clínico intraoral foi observada mobilidade sugestiva de fratura radicular. O exame radiográfico periapical imediato demonstrava presença de núcleo metálico fundido do elemento, porém para a confirmação da fratura e obtenção dos dados de altura e espessura óssea local, solicitou-se complementarmente a tomografia computadorizada cone bean, e já foi prescrito ao paciente que iniciasse a antibioticoterapia com Amoxicilina com Clavulanato de Potássio, de 12/12 horas, por 7 dias.

O exame tomográfico foi realizado pelo paciente e de fato confirmou a fratura radicular, assim como demonstrou haver osso apical à raiz suficiente para a tentativa de uma extração com implante imediato, e havendo torque ideal (acima de $32 \mathrm{~N}$ ) também um provisório imediato sobre implante, como demonstrado nas Figuras 1 e 2.

Figura 1 - Aspecto inicial do sorriso do paciente.

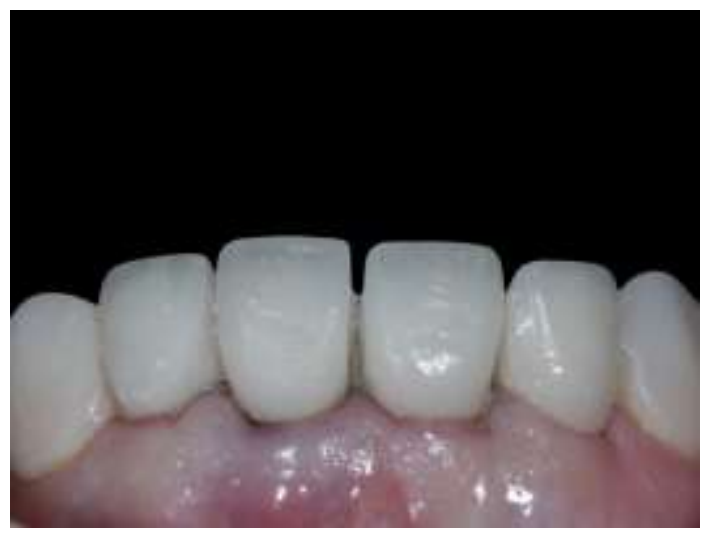

Fonte: Autores (2020). 
Na Figura 1, acima, notar a presença de provisório no elemento 21 e fistula associada. O provisório em questão está sem polimento, explicitado pela rugosidade superficial da resina acrílica selecionada para confecção. Notar ainda a fístula associada à região queratinizada da gengiva que circunda a raíz do elemento.

Figura 2 - Aspecto clínico do elemento extraído. Notar a presença de pino metálico e provisório em resina. Notar ainda a presença de porção radicular do elemento 21.

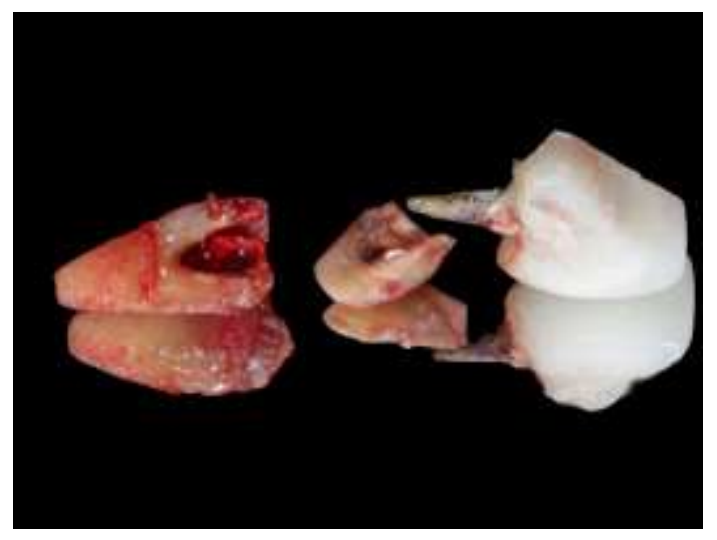

Fonte: Autores (2020).

Na Figura 2, acima, observar o aspecto clínico após a extração do elemento. Notar a presença de núcleo metálico fundido com coroa provisória em resina acrílica. Notar, ainda, a presença de porção radicular fraturada verticalmente, o que pode explicar a presença de fístula.

O tratamento proposto ao paciente foi então a extração atraumática do elemento 21 , instalação imediata de implante, provisionalização imediata do implante caso atingisse torque ideal, preenchimento do Gap vestibular com osso bovino liofilizado e compensação tecidual através de um enxerto de tecido conjuntivo do palato, por vestibular.

Foi realizada a anestesia do nervo alveolar superior e do nervo incisivo com Cloridrato de Mepivacaína $2 \%$ com epinefrina 1:1000.000 (DFL - Rio de Janeiro - Brasil). Foi realizada incisão intra sulcular com lâmina de bisturi 15C (SwannMorton - Sheffield - Inglaterra), sem comprometimento das papilas interditais. Utilizando-se fórceps RoBa (Karl Schumacher Dental - EUA) o elemento foi extraído atraumaticamente, sem movimentos bruscos para preservação máxima da arquitetura gengival e óssea. $\mathrm{O}$ alvéolo foi cuidadosamente curetado e lavado com soro fisiológico estéril, previamente às fresagens para a instalação do implante. Um guia cirúrgico transparente de acetato foi confeccionado a partir da moldagem previa do arco superior, e foi utilizado para guiar o posicionamento das fresas, como exemplificado na Figura 3 abaixo. 
Figura 3 - Guia cirúrgico de acetato confeccionado e em posição para guia de fresagem.

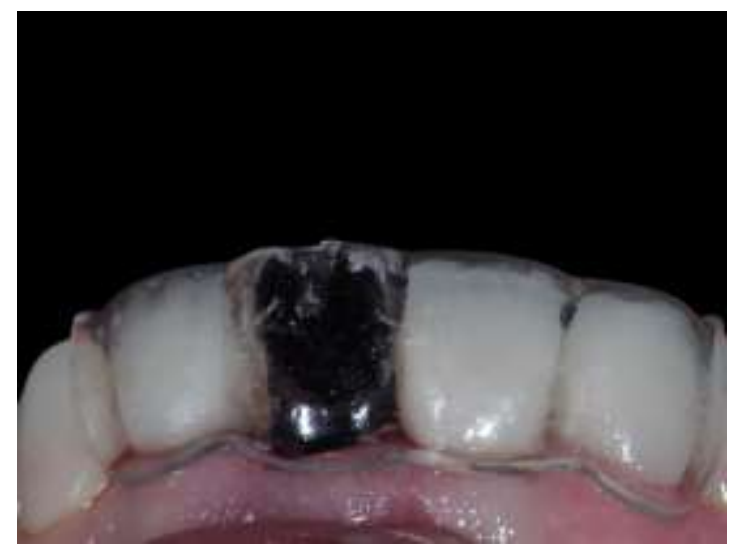

Fonte: Autores (2020).

Na Figura 3, acima, observar o guia cirúrgico de acetato confeccionado para o elemento 21 para direcionar a angulação das fresas para instalação do implante unitário.

Uma sequência de fresas foi utilizada, iniciando-se com a fresa lança, com uma abordagem mais palatina do alvéolo. Em seguida foi utilizada a fresa helicoidal de 2, numa profundidade de $17 \mathrm{~mm}$ a partir da margem gengival, já que o implante de eleição era de 3,5x13 (Cone Morse - Conexão sistemas de prótese - SP - Brasil) e o mesmo seria instalado 4mm subgengivalmente, para assim garantir espaço biológico ideal e também trabalhar adequadamente o perfil de emergência da coroa definitiva. Partiu-se para a fresa helicoidal escalonada de 2,4/2,8 numa profundidade de $17 \mathrm{~mm}$ a partir da margem gengival e por último a fresa helicoidal escalonada 2,8/3,2, apenas $9 \mathrm{~mm}$ a partir da margem gengival, proporcionando uma subfresagem do alvéolo, o que favoreceu o travamento do implante com toque de $45 \mathrm{~N}$, permitindo assim a provisionalização imediata do caso.

Após a instalação do implante foi realizada a tunelização do tecido gengival vestibular, criando espaço suficiente para a fixação do enxerto de tecido conjuntivo. Como definido anteriormente com o paciente, um enxerto de tecido conjuntivo foi planejado para compensar o volume vestibular perdido após a exodontia. O palato também foi anestesiado com Cloridrato de Mepivacaína 2\% com epinefrina 1:1000.000 (DFL - Rio de Janeiro - Brasil), na região do forame palatino maior, e complementando-se na região do desenho da incisão (entre os dentes 23 e 26).

A técnica eleita para a remoção do conjuntivo foi a técnica livre, onde o tecido do palato foi dividido, permanecendo tecido conjuntivo recobrindo o periósteo, como exemplificado pelas Figuras 4 e 5 abaixo. Foi realizada uma manobra compressiva com gaze para minimizar o sangramento, previamente à sutura. A área doadora foi protegida com esponja colágena Hemospon (Maquira - Maringá - PR - Brasil) e realizada sutura em "X” com fio nylon Blue 4-0 (Techsuture - Bauru - SP - Brasil) com nó na regiãovestibular dos elementos 24 e 25.

O enxerto de conjuntivo foi inserido por vestibular na região implantada e fixado com duas suturas, uma em cada extremidade.

Antes do preenchimento do Gap entre o implante e a tábua óssea vestibular, um pilar provisório foi instalado sobre o implante, o qual foi capturado em boca com resina composta e com a coroa antiga do paciente, a qual foi ocada previamente permitindo a livre passagem do pilar. 
Figuras 4 e 5 - Exemplificação clínica da técnica de remoção livre do tecido conjuntivo do palato. Notar o permanecimento do tecido conjuntivo que recobre o periósteo.
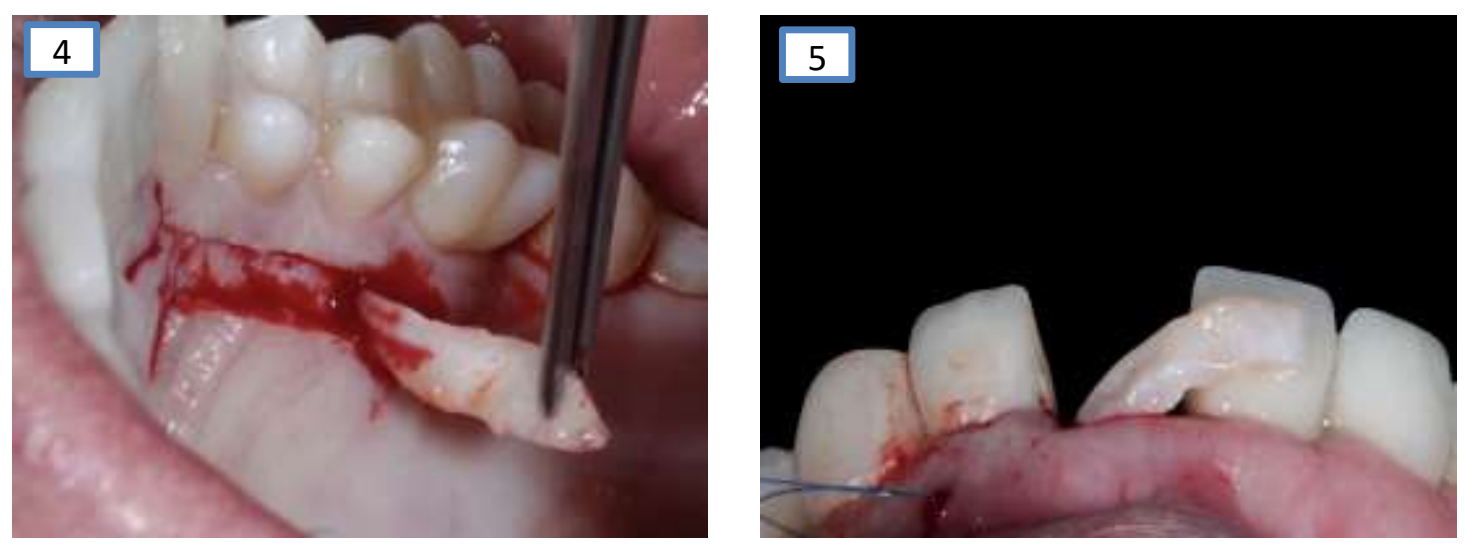

Fonte: Autores (2020).

Na Figura 4, acima, observar clinicamente a remoção do tecido conjuntivo do palato e o permanecimento do tecido conjuntivo que recobre o periósteo. Na Figura 5, notar a sutura do tecido removido do palato na região da extração do elemento 21, com a finalidade de promover maior e melhor cicatrização regional.

O conjunto pilar-coroa foi removido da boca do paciente e fixado ao análogo do implante que estava preso a uma haste (conexão sistema de prótese - SP - Brasil) para facilitar seu manuseio. Foi então determinado o perfil de emergência da coroa, as áreas "crítica" e "sub-crítica", bem como o acabamento e polimento da peça, em especial da porção subgengival. Antes da instalação da coroa, foi realizado o preenchimento do Gap vestibular utilizando-se enxerto homógeno liofilizado bovino de granulação fina (Bio-Oss - Geistlich Pharma), o qual foi delicadamente condensado no Gap, sem muita compressão, como demonstrado na Figura 6 abaixo.

Figura 6 - Exemplificação clínica da inserção do enxerto homogêneo liofilizado bovino de granulação fina no interior da ferida cirúrgica.

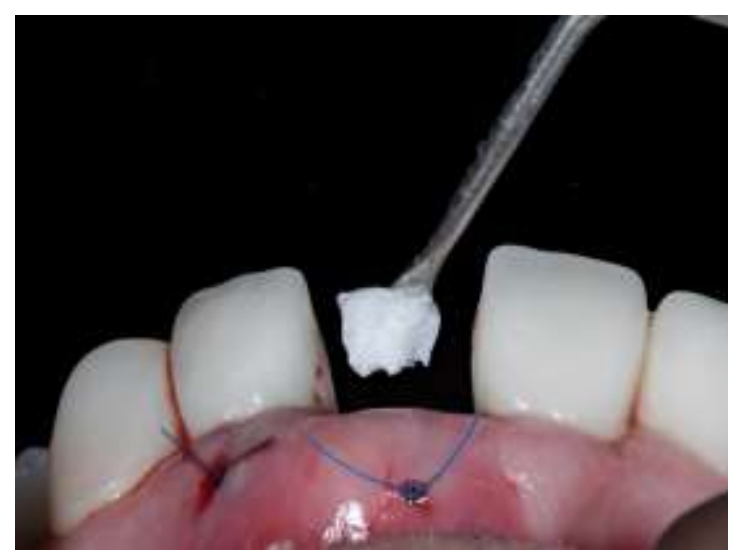

Fonte: Autores (2020).

Na Figura 6, acima, notar a inserção do enxerto homogêneo liofilizado bovino de granulação fina no interior da ferida cirúrgica após a sutura do tecido conjuntivo do palato no interior da ferida cirúrgica do elemento 21.

A coroa provisória foi então parafusada ao implante, e um torque de $20 \mathrm{~N}$ foi aplicado ao parafuso de fixação. A proteção do parafuso foi realizada com fita teflon e o fechamento do orifício do parafuso foi realizado com Resina flow (DFL - Rio de 
Janeiro - Brasil). Ajustes oclusas foram realizados, para que, nos movimentos desoclusivos, não houvesse nenhum tipo de toque na coroa provisória.

Finalmente, suturas suspensórias foram realizadas nas papilas próximais, tracionando-as coronalmente, com o fio nylon Blue 4-0 (Techsuture - Bauru - SP - Brasil). O pós-operatório de 14 dias demonstrou saúde e estabilidade periimplantar. No pósoperatório de 140 dias observou-se um excelente volume vestibular proporcionado pelo enxerto de tecido conjuntivo.

Neste momento iniciou-se os procedimentos de moldagem, com individualização do Transfer com resina flow, para copiar fielmente na coroa definitiva o perfil de emergência obtido com o provisório. O caso foi enviado ao laboratório, o qual confeccionou um pilar metálico, e sobre ele uma coroa de dissilicato de lítio para ser cimentada ao pilar. Cor e forma foram aprovadas pelo paciente, e então partiu-se para a cimentação com cimento resinoso dual Panavia V5 (Kuraray - Japão), conforme exemplificado na Figura 7 abaixo.

Figura 7 - Resultado da instalação da coroa de dissilicato de lítio.

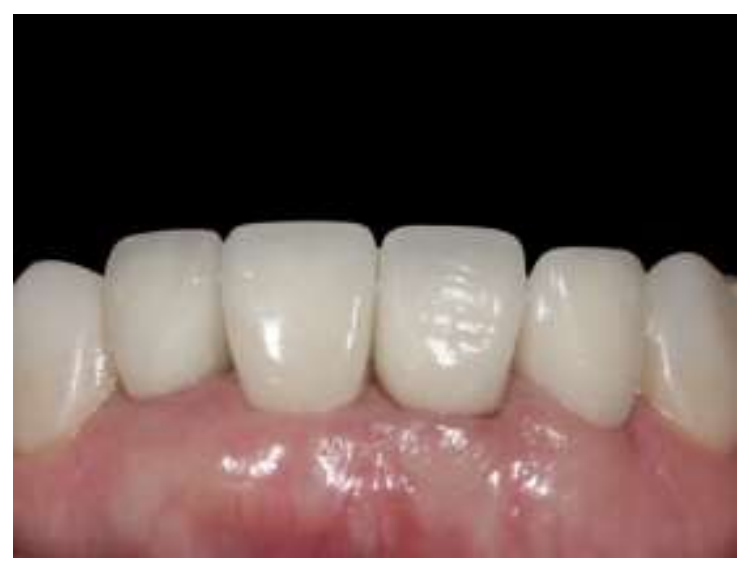

Fonte: Autores (2020).

Na Figura 7, acima, notar o aspecto final com a instalação da coroa de dissilicato de lítio. Notar, ainda, a saúde e estética gengival circunvizinha do elemento 21 , sem a presença de inflamação gengival ou fístula associada ao elemento.

\subsection{Relato de Caso 2}

Paciente do sexo Feminino, 57 anos, compareceu ao atendimento com queixa de mobilidade na coroa do dente 21 e dor ao mastigar. No exame radiográfico imediato notou-se que a raiz era extremamente curta e possuía um pino de fibra de vidro. A paciente não apresentava problemas sistêmicos e era portadora de uma reabilitação completa em cerâmica nos elementos dentais. Ao exame clínico intraoral observou-se que a coroa estava solta, e ao ser removida estava aderida ao pino de fibra de vidro, que também era extremamente curto. A raíz apresentava pouquíssima férula. Foi então solicitada tomografia computadorizada Cone Beam da região para detectar possíveis trincas e também mensurar a disponibilidade óssea local. $\mathrm{O}$ exame tomográfico demonstrou disponibilidade óssea na região e detectou uma trinca radicular.

Foi então proposto à paciente a extração atraumática do elemento 21 com instalação imediata de implante. Caso o implante atingisse torque ideal (acima de $32 \mathrm{~N}$ ) foi também proposta a provisionalização imediata do implante. A compensação de volume vestibular seria realizada através do preenchimento do Gap entre o implante e a tábua óssea com osso bovino liofilizado associado a um enxerto de tecido conjuntivo do palato.

Utilizando-se Cloridrato de Mepivacaína 2\% com epinefrina 1:100.000 (DFL - Rio de Janeiro - Brasil) foi então realizada a anestesia do nervo alveolar superior e do nervo incisivo. Foi realizada incisão intra sulcular com lâmina de bisturi 15 
C (Swann-Morton - Sheffield - Inglaterra), sem envolver as papilas interdentais. Como a raiz era extremamente curta ela pôde ser extraída atraumaticamente utilizando-se apenas o periótomo (Schwert - Seintingen-Oerflacht - Alemanha).

O alvéolo foi então curetado e lavado com soro fisiológico estéril. A partir dos dados tomográficos, o implante de eleição foi um Cone Morse de ápice cônico, 3,3 x 10 mm (Straumann - Basiléia - Suíça).

Partiu-se primeiramente para a coleta do tecido conjuntivo do palato, o qual foi anestesiado com Cloridrato de Mepivacaína 2\% com epinefrina 1:100.000 (DFL - Rio de Janeiro - Brasil), na região do forame palatino maior, e complementando-se na região do desenho da incisão.

O tecido conjuntivo foi removido pela técnica livre, dividindo-se o tecido do palato, para que o periósteo não ficasse exposto. A área doadora foi protegida com esponja colágena Hemospon (Maquira - Maringá -PR - Brasil) e realizada sutura em "X” com fio nylon Blue 4-0 (Techsuture - Bauru - SP - Brasil) com nó na vestibular dos elementos adjacentes.

Iniciou-se o preparo do leito do implante com a fresa lança, com uma abordagem mais palatina. Em seguida foi utilizada a fresa helicoidal de 2,2 a uma profundidade de $14 \mathrm{~mm}$ a partir da margem gengival, pra que o implante ficasse $4 \mathrm{~mm}$ subgengivalmente, garantindo o espaço biológico e a possibilidade de trabalhar adequadamente o perfil de emergência da coroa. A fresa final foi a helicoidal de 2,8, numa profundidade de $10 \mathrm{~mm}$ a partir da margem gengival proporcionando a subfresagem do alvéolo e o travamento do implante com $40 \mathrm{~N}$ de torque, o que possibilitou a provisionalização imediata do caso, conforme demonstrado pela Figura 8 abaixo. Com o implante instalado o tecido gengival vestibular foi tunelizado e sua maleabilidade foi testada através de tracionamento com pinça atraumática (Schwert - Seintingen-Oerflacht - Alemanha).

Figura 8 - Resultado da instalação do implante logo após extração atraumática do elemento 21.

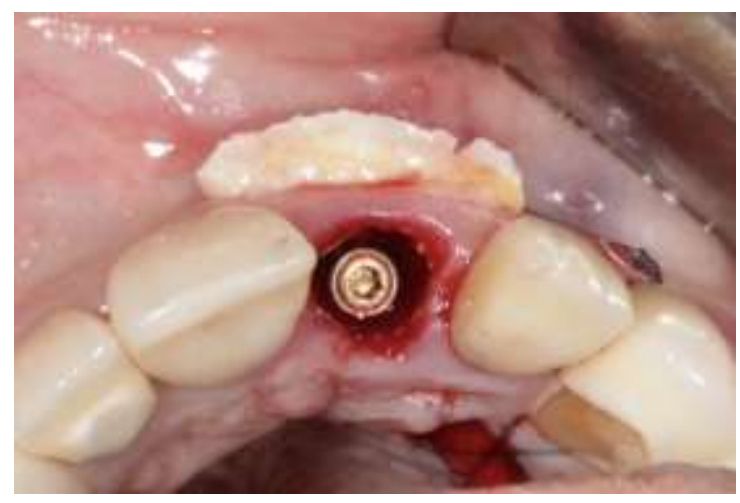

Fonte: Autores (2020).

Na Figura 8, acima, notar o resultado da instalação do implante logo após a extração atraumática do elemento 21 . Notar, ainda, a palatinização do implante, bem como o não rompimento gengival após a extração.

O enxerto de conjuntivo foi desepitelizado previamente à sua inserção por vestibular na região implantada e fixado através de suturas em suas extremidades (fio nylon Blue 5-0 / Techsuture - Bauru - SP - Brasil).

A coroa antiga da paciente pôde ser aproveitada deixando-a oca e com uma abertura na face palatina, para a passagem do pilar provisório, o qual foi instalado sobre o implante e capturado em boca com resina composta. O conjunto pilar-coroa foi removido da boca da paciente para receber ajustes e polimento adequado, assim como a determinação das áreas "crítica" e "subcrítica”. O preenchimento do Gap vestibular foi realizado utilizando-se enxerto homógeno liofilizado bovino de granulação fina (Bio-Oss - Geistlich Pharma), o qual foi delicadamente condensado no Gap, sem muita compressão.

A coroa provisória foi então parafusada ao implante com um torque de $20 \mathrm{~N}$ e o parafuso foi protegido e vedado com com fita teflon e Resina flow (DFL - Rio de Janeiro - Brasil), respectivamente. A coroa provisória ficou curta após os necessários 
ajustes oclusais, conforme explicitada na Figura 9 abaixo, no entanto a paciente estava ciente da importância da ausência de qualquer interferência nos movimentos desoclusivos.

Figura 9 - Resultado imediato após aparafusamento da coroa provisória do elemento 21.

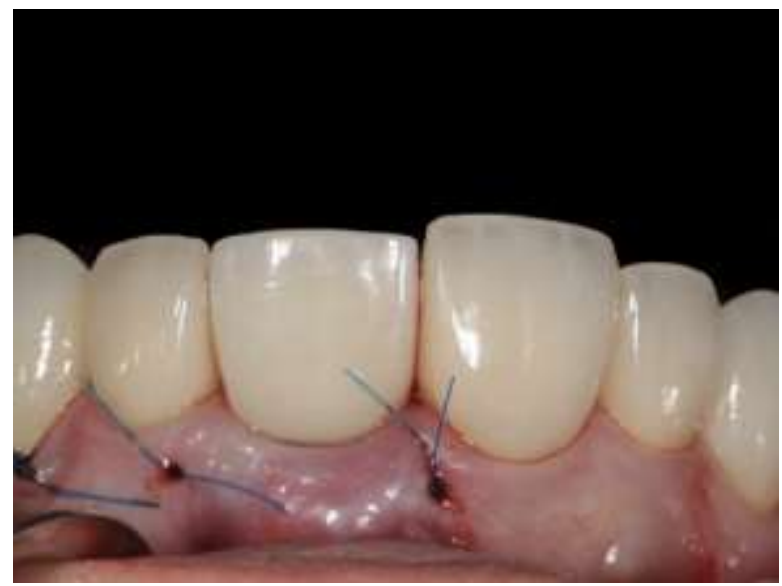

Fonte: Autores (2020).

Na Figura 9, acima, notar o resultado imediato após aparafusamento da coroa provisória do elemento 21. Notar, ainda, seu menor comprimento cérvico-incisal em relação ao dente vizinho, decorrente da necessidade da não interferência oclusal durante os movimentos funcionais.

Devido à pouquíssima alteração na arquitetura gengival, não foi necessário realizar suturas suspensórias na região. Em 18 dias realizou-se o primeiro pós-operatório onde se observava-se adequada estabilidade tecidual e saúde peri-implantar. Em 90 dias já se observava completa cicatrização da área, com excelente volume de tecido vestibular.

Os procedimentos protéticos foram então iniciados e para que se copiasse o perfil gengival obtido pela coroa provisória, o transferente foi individualizado com resina flow, para então realizar-se a moldagem.

Um pilar personalizado parafusado em zircônia foi provado 20 dias após a moldagem (Aliança Prótese Odontológica SP - Brasil). Optou-se pelo pilar estético uma vez que a paciente já possuía reabilitação cerâmica nos dentes vizinhos, e o desafio seria simular da melhor maneira possível, a cor e a forma do elemento 11. A coroa foi então entregue 10 dias após a prova do pilar, e recebeu um torque de $20 \mathrm{~N}$ no parafuso de fixação, o qual foi vedado e selado com fita de teflon e resina flow.

No acompanhamento de 13 meses observa-se fechamento total da papila incisiva e uma excelente estabilidade de margem e de volume, assim como perfeita saúde periimplantar, conforme exemplificado na Figura 10 abaixo.

Figura 10 - Resultado clínico após instalação da coroa definitiva do elemento 21.

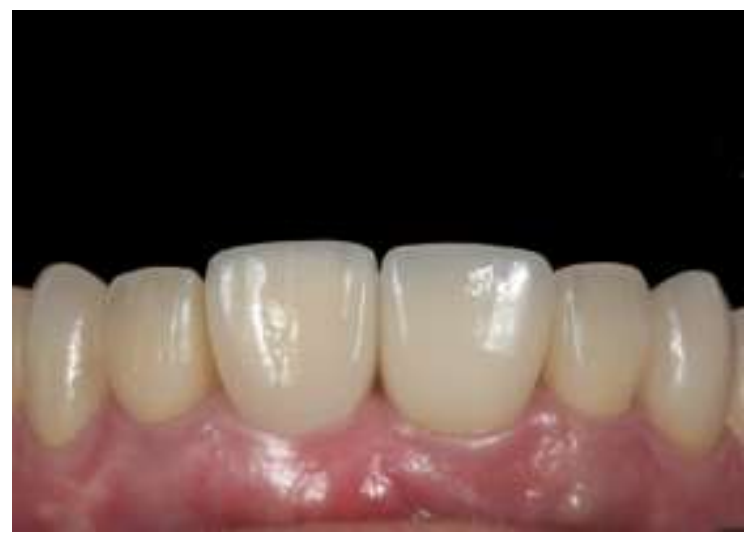

Fonte: Autores (2020). 
Na Figura 10, acima, notar o resultado clínico após instalação da coroa definitiva do elemento 21. Notar, ainda, a qualidade, saúde e estética do tecido gengival circunvizinho ao elemento.

\section{Resultados e Discussão}

Segundo Araujo 2005 e demais colaboradores a percepção do paciente do ponto de vista estético é significativamente diferente dos profissionais dentistas, o que no caso acima relatada nos traz um ganho estético e funcional muito grande da resolução do caso, mas para os pacientes o ganho estético e funcional do reestabelecimento do elemento dentário perdido e maior se feita esta comparação, pelo simplês fato da resolução do problema e do ganho relacionado à auto estima dos pacientes.

O principal objetivo do protocolo cirurgico é o aumento do contorno das paredes ósseas para suportar os tecidos moles e obter um contorno esteticamente saudável e agradavéis em particular reduzir o risco de uma recessão da mucosa, estes parâmetros também foram respeitados no estudo de Yang 2019 e colaboradores para reestabelecer dentes ausentes em região anterior.

De acordo com Bleser 2019 são citados alguns parâmetros que seriam questionáveis no que diz respeito a reabilitação anterior e o resultado estético como a cor, textura, convexidade facial do tecido peri implantar, são aspectos puramente estéticos e igualmente importantes quanto aos parâmetros que se relacionam de forma direta com o estado dos tecidos moles em torno de um dente natural. A adaptação da coroa definitiva permite um perfil de emergência que pode auxiliar adaptação do tecido assim como relatado por Cosyn et al 2012.

A finalidade de procedimentos de enxerto para ganho de espessura da mucosa é um aumento no contorno, predominantemente para fins estéticos e para manutenção da saúde peri-implantar. Evidências recentes sugerem que locais de implante com enxertos de substitutos de tecidos moles ou enxertos com biomateriais resultam em níveis de osso marginal mais estavéis e saúde peri-implantar superior, o que também foi comprovado por estudos de (Giannobile et al, 2018, Thoma et al, 2018).

Os procedimentos de enxerto de tecido mole são frequentemente realizados nos implantes por razões estéticas e biológicas o que foi comprovado por (Chen e Buser, 2014; Hammerle \& Tarnow, 2018). O que pode ser comprovado no estudo realizado que a enxertia de biomateriais e tecido em região anterior após a reabilitação com implante faz diferença no resultado final da prótese definitiva e longevidade do tratamento, assim como a estética final.

Implantes dentários com reconstruções usando biomaterial e enxertia de tecido demosntram altas taxas de sobrevivência segundo (Jung et al, 2012). O contorno gengival é uma medida de resultados relevantes que conforme visto em até 6 meses de acompanhamento em um estudo de Thoma et al 2020, revelou uma espessura estável da mucosa ou até mesmo um pequeno ganho.

Com base em estudos clínicos e sistemáticos a espessura e qualidade do tecido mole parecem desempenhar um papel importante na manutenção ou melhoria da saúde peri implantar o que foi comprovado por (Roccuzo et al 2017; Thoma et al 2018). Esses dados indicam o efeito biológico dos procedimentos de enxerto para ganho de espessura da mucosa nos locais com implantes. No estudo de Thoma et al 2020 os tecidos peri implantares permaneceram saudáveis, em ambos os grupos de tratamento, o que pode ser observado nos casos mencionados á cima com um acompanhamento de mais de um ano, foi preservado a saúde dos tecidos e os contornos gengivais.

Um dos pontos chaves para permitir que os contornos se mantenham naturais, respeitando seu volume e forma esta relacionado à escolha do abutment (Ottoni et al, 2005). O perfil de emergência adequado de um implante é compátivel com a prótese por isso é importante aperfeiçoar a higiene e estética, é fundamental alcançar a arquitetura harmoniosa de tecidos moles em torno dos implantes dentários antes da instalação da prótese definitiva. Para aquisição deste objetivo são necessárias as modificações graduais que podem ser obtidas com o uso de prótese provisórias, sendo que estas poderão refletir em uma 
estabilidade do material enxertado e das mudanças do tecido mole para a sua cicatrização, obtendo o contorno necessário (Carrera et al, 2019).

O carregamento imediato ainda é um assunto controverso, um estudo confirmou que as txas de falha do implante com carga imediata não são menores quando comparados com os implantes carregados de forma tardia, não houve diferenças estatistícas entre o carregamento imediato e o tardio. (Carrera et al, 2019).

Sendo assim o imediato nos possibilita um tratamento mais rápido, favorecendo assim a arquitetura do tecido mole, para a obtenção deste resultado é necessária uma alta estabilidade primária. Nos casos mencionados foi possível a instalação de prótese provisória, o que possibilitou a manutenção de todo o desenho do tecido mole, que juntamento com a enxertia tiveram um papel determinante para o sucesso dos casos.

\section{Conclusão}

O presente estudo demonstrou, através de dois casos clínicos, que a instalação de implantes imediatos com provisionalização também imediata, seguida da utilização de enxerto ósseo com biomaterial e compensação tecidual com enxerto de tecido conjuntivo, é uma modalidade de tratamento previsível, demonstrando resultados satisfatórios e estáveis em área estética.

Tais achados confirmam a idéia de que as estéticas branca e vermelha caminham lado a lado, e que os implantes podem ser instalados em áreas anteriores de forma imediata, desde que respeitado-se os aspectos ósseos e gengivais de cada caso, para assim alcançar resultados biológicos e estéticos favoráveis.

Sugere-se, para futuras pesquisas, trabalhos que abordem a questão fisiológica envolvida no processo de reparo e cicatrização tecidual frente a essa forma de restauração do sistema estomatognático. Ainda, sugere-se pesquisas que busquem elucidar o comportamento tecidual celular no reparo.

\section{Referências}

Araujo, M. G., \& Lindhe, J. (2005). Dimensional ridge alterations following tooth extraction. An experimental study in the dog. Journal of Clinical Periodontology, 32(2), 212-218.

Araujo, M. G., Sukekava, F., Wennstrom, J. L., \& Lindhe, J. (2005). Ridge alterations following implant placement in fresh extraction sockets: an experimental study in the dog. Journal of Clinical Periodontology, 32(6), 645-652.

Botticelli, D., Berglundh, T., \& Lindhe, J. (2004). Hard-tissue alterations following immediate implant placement in extraction sites. Journal of Clinical Periodontology, 31(10), 820-828.

Bhola, M., Neely, A. L., \& Kolhatkar, S. (2008). Immediate Implant Placement: Clinical Decisions, Advantages, and Disadvantages. Journal of Prosthodontics, $17(7), 576-581$

Boardman, N., Darby, I., \& Chen, S. (2015). A retrospective evaluation of aesthetic outcomes for single-tooth implants in the anterior maxilla. Clinical Oral Implants Research, 27(4), 443-451.

Belser, U. C., Grütter, L., Vailati, F., Bornstein, M. M., Weber, H. P., \& Buser, D. (2009). Outcome Evaluation of Early Placed Maxillary Anterior Single-Tooth Implants Using Objective Esthetic Criteria: A Cross-Sectional, Retrospective Study in 45 Patients With a 2- to 4-Year Follow-Up Using Pink and White Esthetic Scores. Journal of Periodontology, 80(1), 140-151.

Botilde, G., Colin, P., González-Martín, O., Lecloux, G., Rompen, E., \& Lambert, F. (2020). Hard and soft tissue analysis of alveolar ridge preservation in esthetic zone using deproteinized bovine bone mineral and a saddle connective tissue graft: A long-term prospective case series. Clinical Implant Dentistry and Related Research, 22(3):387-396.

Cosyn, J., De Bruyn, H., \& Cleymaet, R. (2012). Soft Tissue Preservation and Pink Aesthetics around Single Immediate Implant Restorations: A 1-Year Prospective Study. Clinical Implant Dentistry and Related Research, 15(6), 847-857.

Jiang, X., Di, P., Ren, S., Zhang, Y., \& Lin, Y. (2020). Hard and soft tissue alterations during the healing stage of immediate implant placement and provisionalization with or without connective tissue graft: A randomized clinical trial. Journal of Clinical Periodontology, 47(8).

Giannobile, W. V., Jung, R. E., \& Schwarz, F. (2018). Evidence-based knowledge on the aesthetics and maintenance of peri-implant soft tissues: Osteology Foundation Consensus Report Part 1-Effects of soft tissue augmentation procedures on the maintenance of peri-implant soft tissue health. Clinical Oral Implants Research, 29, 7-10. 
Merheb, J., Quirynen, M. \& Teughels, W. (2014) Critical buccal bone dimensions along implants. Periodontology 2000, 66, 97-105.

Noelken, R., Moergel, M., Pausch, T., Kunkel, M., \& Wagner, W. (2018). Clinical and esthetic outcome with immediate insertion and provisionalization with or without connective tissue grafting in presence of mucogingival recessions: A retrospective analysis with follow-up between 1 and 8 years. Clinical Implant Dentistry and Related Research, 20(3), 285-293.

Ottoni, J. M. P., Oliveira, Z. F. L., Mansini, R., \& Cabral, A. M. (2005). Correlation between placement torque and survival of single-tooth implants. Int J Oral Maxillofac Implants, 20(5):769-776.

Rojo, E., Stroppa, G., Sanz-Martin, I., Gonzalez-Martín, O., \& Nart, J. (2020). Soft tissue stability around dental implants after soft tissue grafting from the lateral palate or the tuberosity area - a randomized controlled clinical study. Journal of Clinical Periodontology, 47(7):892-899.

Ruales-Carrera, E., Pauletto, P., Apaza-Bedoya, K., Volpato, C. A. M., Özcan, M., \& Benfatti, C. A. M. (2019). Peri-implant tissue management after immediate implant placement using a customized healing abutment. Journal of Esthetic and Restorative Dentistry, 31(6):533-541.

Seyssens, L., De Lat, L., \& Cosyn, J. (2020). Immediate implant placement with or without connective tissue graft: a systematic review and meta-analysis. Journal of Clinical Periodontology, 48(2):284-301.

Tatum, C., Saltz, A., Prihoda, T., DeGroot, B., Mealey, B., Mills, M., \& Huynh-Ba, G. (2020). Management of Thick and Thin Periodontal Phenotypes for Immediate Dental Implants in the Esthetic Zone: A Controlled Clinical Trial. The International Journal of Periodontics \& Restorative Dentistry, 40(1), 51-59.

Thoma, D. S., Gasser, T. J. W., Jung, R. E., \& Hämmerle, C. H. F. (2020). Randomized controlled clinical trial comparing implant sites augmented with a volume-stable collagen matrix or an autogenous connective tissue graft: 3-year data after insertion of reconstructions. Journal of Clinical Periodontology, 47(5):630-639.

Thoma, D. S., Naenni, N., Figuero, E., Hämmerle, C. H. F., Schwarz, F., Jung, R. E., \& Sanz-Sánchez, I. (2018). Effects of soft tissue augmentation procedures on peri-implant health or disease: A systematic review and meta-analysis. Clinical Oral Implants Research, 29, 32-49.

Van Nimwegen, W. G., Raghoebar, G. M., Zuiderveld, E. G., Jung, R. E., Meijer, H. J. A., \& Mühlemann, S. (2018). Immediate placement and provisionalization of implants in the aesthetic zone with or without a connective tissue graft: A 1-year randomized controlled trial and volumetric study. Clinical Oral Implants Research, 29(7), 671-678.

Zuiderveld, E. G., Meijer, H. J. A., den Hartog, L., Vissink, A., \& Raghoebar, G. M. (2017). Effect of connective tissue grafting on peri-implant tissue in single immediate implant sites: A RCT. Journal of Clinical Periodontology, 45(2), 253-264.

Yang, X., Zhou, T., Zhou, N., \& Man, Y. (2019). The thickness of labial bone affects the esthetics of immediate implant placement and provisionalization in the esthetic zone: A prospective cohort study. Clinical Implant Dentistry and Related Research, 21(3):482-491.

Younes, F., Eghbali, A., De Bruyckere, T., Cleymaet, R., \& Cosyn, J. (2018). A randomized controlled trial on the efficiency of free-handed, pilot-drill guided and fully-guided implant surgery in partially edentulous patients. Clinical Oral Implants Research, 30(2):131-138. 